\title{
Molecular Detection of Microorganisms in Distal Airways of Patients Undergoing Lung Cancer Surgery
}

\author{
Xavier Benoit D'Journo, MD, PhD, Fadi Bittar, MD, PhD, Delphine Trousse, MD, \\ Francoise Gaillat, MD, Christophe Doddoli, MD, Herve Dutau, MD, \\ Laurent Papazian, MD, PhD, Didier Raoult, MD, PhD, Jean Marc Rolain, MD, PhD, and \\ Pascal Alexandre Thomas, MD
}

Department of Thoracic Surgery and Diseases of the Esophagus, Aix-Marseille University and Assistance Publique-Hôpitaux de Marseille, Hôpital Nord; URMITE, CNRS-IRD UMR 6236, Faculté de Médecine et de Pharmacie, Aix-Marseille University, Marseille; and the Departments of Anesthesiology, Intensive Care in Medicine, and Pleural Disease and Interventional Pulmonology, Hôpital Nord; Aix-Marseille University and Assistance Publique-Hôpitaux de Marseille, Marseille, France

Background. Whereas proximal airways of patients undergoing lung cancer surgery are known to present specific microbiota incriminated in the occurrence of postoperative respiratory complications, little attention has been paid to distal airways and lung parenchyma considered to be free from bacteria. We have hypothesized that molecular culture-independent techniques applied to distal airways should allow identification of uncultured bacteria, virus, or emerging pathogens and predict the occurrence of postoperative respiratory complications.

Methods. Microbiological assessments were obtained from the distal airways of resected lung specimens from a prospective cohort of patients undergoing major lung resections for cancer. Microorganisms were detected using real-time polymerase chain reaction (PCR) assays targeting the bacterial 16s ribosomal RNA gene and Herpesviridae, cytomegalovirus (CMV), and herpesvirus simplex. All postoperative microbiological assessments were compared with the PCR results.

Results. In all, 240 samples from 87 patients were

$\mathrm{T}^{\circ}$ date, postoperative respiratory complications remain the most frequent and serious complications after lung cancer resection and are the primary cause of hospital death after surgery [1]. A vast majority of this heterogeneous group of diseases result from infectious bacterial etiologies, but a large number of them are frequently undetermined owing to inconclusive postoperative microbiological results [2-5].

Because infectious etiologies have been highly incriminated in the occurrence of these postoperative events, bronchial colonization has been suggested to be an essential factor in the pathogenesis of these complications [5-11]. Proximal airway colonization is present in

Address correspondence to Dr D'Journo, Department of Thoracic Surgery, Hôpital Nord, Chemin des Bourrely, 13915, Marseille Cedex 20, France; e-mail: xavier.djourno@ap-hm.fr. investigated. Colonizing agents were exclusively Herpesviridae $(\mathrm{CMV}, \mathrm{n}=13$, and herpesvirus simplex, $\mathrm{n}=1)$. All 16s ribosomal RNA PCR remained negative. Thirteen patients $(15 \%)$ had a positive CMV PCR (positive-PCR group), whereas the remaining 74 patients constituted the negative-PCR group. Postoperative pneumonia occurred in $24 \%$ of the negative-PCR group and in $69 \%$ of the positive-PCR group ( $p=0.003$ ). Upon stepwise logistic regression, performance status, percent of predicted diffusion lung capacity for carbon monoxide, and positive PCR were the risk factors of postoperative respiratory complications. The CMV PCR had a positive predictive value of 0.70 in prediction of respiratory complications.

Conclusions. When tested by molecular techniques, lung parenchyma and distal airways are free of bacteria, but CMV was found in a high proportion of the samples. Molecular CMV detection in distal airways should be seen as a reliable marker to identify patients at risk for postoperative respiratory complications.

$18 \%$ to $41 \%$ of patients undergoing lung cancer surgery [12]. Hemophilus influenzae, Streptococcus pneumoniae, and Staphylococcus aureus constitute the main microbiota found in the proximal bronchial tree of these active/ exsmokers and chronic obstructive pulmonary disease patients.

Whereas proximal airways are notoriously contaminated by a specific microbiota of potential pathogenic microorganisms, microbiological results concerning the distal airways and lung parenchyma at the moment of surgery remain conflicting $[5,8,13]$. That can be explained by current methods of microbiological identification, mainly based on traditional phenotypic methods of cultures, precluding definitive identification when considering that detection and identification of a majority of microbiological species requires modern culture techniques [14, 15]. Moreover, bacteria are not the sole 


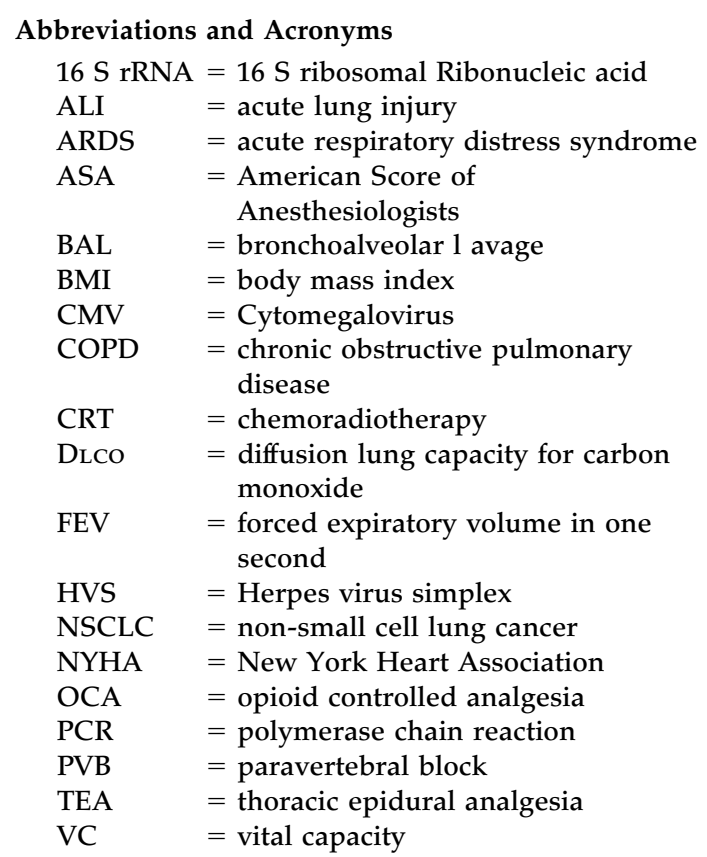

pathogenic microorganisms implied in the development of these respiratory failures. Part of the pathogenesis of respiratory complications may be largely influenced by other potential pathogenic microorganisms, such as cytomegalovirus (CMV), which are considered to be potential causes of postoperative respiratory infections [16, 17].

Because the development of microbiology has obviated the requirement to culture microbes to identify them [18-20], we have hypothesized that molecular cultureindependent techniques applied to distal airways and lung parenchyma of patients undergoing lung cancer surgery should allow the identification of uncultured bacteria, viruses, or emerging pathogens. In addition, we have investigated the correlation between the results of this molecular detection and the occurrence of postoperative respiratory complications to provide an early reliable biologic marker to predict respiratory failure.

\section{Material and Methods}

\section{Study Design}

This study was conducted according to the current regulations for clinical research in France. This study was financially supported by the University of the Mediterranean and the Assistance Publique-Hôpitaux de Marseille, after approval by the Institutional Review Board (French Society of Thoracic and Cardiovascular Surgery IRB; CERC-SFCTCV-2011-6-24-15-52-38-D-Xa). Informed consent was obtained from all patients before surgery.

All patients undergoing major lung resection between February 1, 2009, and October 31, 2009, for lung cancer without signs of acute respiratory infection were eligible for this study. Patients treated with antibiotics (be- cause of respiratory or extrarespiratory infections) during the week preceding the surgery were excluded from the study. All patients received a planned protocol for antibiotic prophylaxis, according to the current French recommendations [5]. All the data concerning patient characteristics, results of microbiological studies, treatment procedures, and outcome were prospectively collected. All patients were intubated with a double-lumen endobronchial tube to perform single-lung ventilation. Lung resections were performed according to standard techniques. Side, type of resection, possible associated sleeve bronchial or chest wall resection, previous thoracotomy, and total procedure time were recorded. Postoperative outcome was collected prospectively.

\section{Perioperative Microbiological Samples}

During the surgical procedure and immediately after lung resection, a guided bronchoalveolar lavage (BAL) was performed on the resected specimen with a standardized protocol: $50 \mathrm{~mL}$ physiologic saline was instilled into the opened bronchus of the resected lung. Fluid return was collected using a sterile suction catheter equipped with a mucus collection tube. Biopsies were taken from resected specimens of healthy and tumoral lungs for microbiological examination.

Microbiological analysis was undertaken through a standardized protocol of DNA and RNA extraction for polymerase chain reaction (PCR) sequencing and amplification to exclude a possible colonization of the airways [20-23]. The PCR assays were performed in two sets of experiments for all samples to confirm the results. Patients were considered to be colonized if at least one of the two repeated PCR assays was positive for potential pathogenic microorganisms. This group of patients constituted the "positive-PCR group," whereas patients with negative PCR results constituted the "negative-PCR group." An association between positive PCR and postoperative respiratory complications was investigated secondarily by screening all the patients' medical charts. Comparison between preoperative and postoperative samples was investigated to draw microbiological concordance between the two events. Lastly, all potential factors incriminated in the occurrence of postoperative respiratory complications were included in a logistic regression. Factors involved in the occurrence of positive PCR were also identified.

\section{Postoperative Complications}

Respiratory complications were defined by all medical events concerning lung parenchyma (ie, sputum retention, atelectasis, pneumonia, acute lung injury, acute respiratory distress syndrome) in the absence of early surgical complications [5,24]. Our general policy was to maintain a high clinical suspicion for postoperative respiratory infections and to document respiratory infection whenever possible. In spontaneously breathing patients, we used quantitative cultures of aspirates obtained by fiberoptic bronchoscopic or bronchoscopic BAL. In intubated patients, we performed bronchoscopic BAL or endotracheal aspirates. Additional details regard- 
Table 1. Clinical Characteristics Among the 87 Included Patients and According to Positive or Negative PCR Status

\begin{tabular}{|c|c|c|c|c|}
\hline Clinical Characteristics & $\begin{array}{c}\text { All } \\
\mathrm{n}=87\end{array}$ & $\begin{array}{c}\text { Negative PCR } \\
\mathrm{n}=74\end{array}$ & $\begin{array}{c}\text { Positive PCR } \\
n=13\end{array}$ & $p$ Value \\
\hline \multicolumn{5}{|l|}{ Preoperative clinical status } \\
\hline Age, years & $63.1 \pm 9$ & $62.7 \pm 9$ & $65.3 \pm 9$ & 0.359 \\
\hline Sex male & $62(71)$ & $52(70)$ & $10(76)$ & 0.452 \\
\hline Weight, kg & $72.8 \pm 21$ & $71 \pm 18$ & $73 \pm 29$ & 0.785 \\
\hline Performance status & $0.21 \pm 0.4$ & $0.19 \pm 0.4$ & $0.31 \pm 0.4$ & 0.396 \\
\hline BMI & $24 \pm 3$ & $24 \pm 4$ & $25 \pm 3$ & 0.264 \\
\hline Charlson score & $4.7 \pm 1.0$ & $4.8 \pm 1.0$ & $4.4 \pm 1.0$ & 0.611 \\
\hline $\mathrm{FEV}_{1} \%$ of predicted & $83 \pm 18$ & $84 \pm 18$ & $78 \pm 18$ & 0.238 \\
\hline DLCO $\%$ of predicted & $72 \pm 12$ & $73 \pm 11$ & $66 \pm 16$ & 0.073 \\
\hline \multicolumn{5}{|l|}{$\begin{array}{l}\text { Preoperative risk factors for } \\
\text { respiratory complications }\end{array}$} \\
\hline NSCLC & $74(85)$ & $63(85)$ & $11(84)$ & 0.619 \\
\hline Smoking history & $79(90)$ & $66(90)$ & $13(100)$ & 0.259 \\
\hline Smoking cessation (79 smokers) & $57(72)$ & $48(64)$ & $9(69)$ & 0.720 \\
\hline Smoking pack-year & $41 \pm 25$ & $40 \pm 25$ & $50 \pm 24$ & 0.178 \\
\hline Alcohol & $10(1)$ & $7(9)$ & $3(23)$ & 0.167 \\
\hline COPD & $33(38)$ & $27(36)$ & $6(46)$ & 0.357 \\
\hline Diabetes mellitus & $12(13)$ & $8(11)$ & $4(30)$ & 0.076 \\
\hline Previous cancer & $28(32)$ & $24(32)$ & $4(31)$ & 0.591 \\
\hline Previous CRT & $23(26)$ & $21(29)$ & $2(15)$ & 0.271 \\
\hline Neoadjuvant CRT & $9(10)$ & $7(10)$ & $2(15)$ & 0.403 \\
\hline ASA score & $1.98 \pm 0.5$ & $1.9 \pm 0.5$ & $2.2 \pm 0.5$ & 0.323 \\
\hline NHYA score & $1.6 \pm 0.5$ & $1.6 \pm 0.5$ & $1.8 \pm 0.5$ & 0.093 \\
\hline Previous cardiac disease & $12(14)$ & $9(12)$ & $3(23)$ & 0.253 \\
\hline Hypertension & $12(14)$ & $9(12)$ & $3(23)$ & 0.390 \\
\hline \multicolumn{5}{|l|}{ Details of operation } \\
\hline Segmental resection & $4(4)$ & $3(4)$ & $1(7)$ & 0.536 \\
\hline Lobectomy & $73(83)$ & $61(82)$ & $12(92)$ & \\
\hline Sleeve lobectomy & $7(8)$ & $6(8)$ & $1(6)$ & \\
\hline Pneumonectomy & $3(3)$ & $3(4)$ & $0(0)$ & \\
\hline Chest wall en-bloc resection & $2(2)$ & $2(2)$ & $0(0)$ & \\
\hline Previous thoracic surgery & $5(5)$ & $3(4)$ & $2(16)$ & 0.159 \\
\hline Side, right/left & $54 / 33$ & $46 / 28$ & $5 / 8$ & 1.000 \\
\hline Analgesia TEA/PVB/OCA & $68 / 18 / 4$ & $57 / 13 / 4$ & $8 / 5 / 0$ & - \\
\hline
\end{tabular}

Data presented as $\mathrm{n}(\%)$ or mean $\pm \mathrm{SD}$, unless otherwise indicated.

ASA = American Society of Anesthesiologists; $\quad$ BMI = body mass index; $\quad$ COPD = chronic obstructive pulmonary disease; $\quad$ RT =

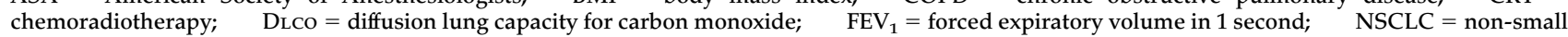
cell lung cancer; $\quad$ NYHA $=$ New York Heart Association; $\quad$ OCA = opioid-controlled analgesia; $\quad$ PCR = polymerase chain reaction; $\quad$ PVB = paravertebral block; $\quad$ TEA $=$ thoracic epidural analgesia.

ing the definitions of postoperative complications are provided in the online data supplement.

\section{Statistical Analysis}

Data were analyzed using the SPSS 17.0 package (SPSS, Chicago, IL). The results are expressed as the mean \pm SD or median (range) for quantitative variables and as percentages for qualitative variables. The Mann-Whitney $U$ test was used for quantitative variables. The Pearson $\chi^{2}$ or Fisher exact test was applied for qualitative variables. To discriminate the risk factors of postoperative complications and risks factors of positive PCR, we have conducted two univariate analyses. All variables using $p$ values less than 0.1 in univariate analysis were included in a logistic regression model. Because of the small simple size, we have opted for stepwise logistic regression with adjustment of confounders with validation by the Homer-Lemeshow test to avoid multicollinearity effect. All $p$ values less than 0.05 were considered to indicate statistical significance.

\section{Results}

Over a 9-month period, 87 consecutive patients were included in the study after informed consent. There were 62 men and 25 women with a mean age of $63 \pm 9$ years. Table 1 summarizes the patients' main characteristics. 
Table 2. Results of Repeated Real-Time Polymerase Chain Reaction Assays Performed on 241 Samples Obtained From 87 Patients $^{a}$

\begin{tabular}{|c|c|c|c|c|}
\hline Real-Time PCR Assay & BAL & $\begin{array}{l}\text { LB From Healthy } \\
\text { Lung }\end{array}$ & $\begin{array}{l}\text { LB From Tumoral } \\
\text { Lung }\end{array}$ & $\begin{array}{l}\text { Total Patients With } \\
\text { Positive PCR }\end{array}$ \\
\hline Number of samples & 79 & 85 & 77 & \\
\hline RNA extraction & 79 & 85 & 77 & \\
\hline Number of samples analyzed & 79 & 85 & 77 & \\
\hline \multicolumn{5}{|l|}{ Albumin } \\
\hline+ & 79 & 77 & 76 & \\
\hline- & 0 & 0 & $1^{\mathrm{b}}$ & \\
\hline \multicolumn{5}{|l|}{ 16s rRNA } \\
\hline 2 positive rt-PCR & 0 & 0 & 0 & 0 \\
\hline 1 positive rt-PCR & 0 & 0 & 0 & \\
\hline Negative & 79 & 85 & 77 & \\
\hline \multicolumn{5}{|l|}{ HVS } \\
\hline 2 positive rt-PCR & 0 & 0 & 1 & 1 \\
\hline 1 positive rt-PCR & 1 & 0 & 0 & \\
\hline Negative & 78 & 77 & 76 & \\
\hline \multicolumn{5}{|l|}{ CMV } \\
\hline 2 positive rt-PCR & 4 & 5 & 2 & $13^{\mathrm{c}}$ \\
\hline 1 positive rt-PCR & 3 & 0 & 0 & \\
\hline Negative & 72 & 72 & 75 & \\
\hline
\end{tabular}

a Patients were considered to be positive if at least one of the two repeated polymerase chain reaction (PCR) assays proved positive for potential pathogenic microorganisms. $\quad{ }^{b}$ Samples excluded from the analysis owing to insufficient DNA material. ${ }^{\mathrm{c}}$ One patient had a coinfection with cytomegalovirus (CMV) and herpesvirus simplex (HVS).

$\mathrm{BAL}=$ bronchoalveolar lavage $\quad \mathrm{LB}=$ lung biopsy $\quad \mathrm{PCR}=$ polymerase chain reaction; $\quad$ rRNA $=$ ribosomal $\mathrm{RNA} ; \quad$ rt $=$ real time.

\section{PCR Results of the Distal Airways}

From the total cohort of 87 patients, a total of 241 samples were collected: 79 from BAL, 85 from healthy lungs, and 77 from lung tumors. These data represent a mean of 2.7 samples per patient. All samples were suitable for repeated real-time PCR amplification. The PCR of albumin and human actin genes was performed to test the quality of extracted DNA. Table 2 summarizes these PCR results. Of the 241 samples, one sample was excluded from the analysis owing to a lack of DNA material. From the remaining 240 samples, positive PCR was obtained in 16 samples $(6.3 \%)$ from 13 patients. These 13 patients $(15 \%$ of the total cohort) constituted the positive-PCR group (6 in BAL, 5 in lung biopsies, and 2 in both). Pathogenic microorganisms were detected by positive PCR and found to be exclusively Herpesviridae (CMV, $\mathrm{n}=12, \mathrm{CMV}$ and herpesvirus simplex, $\mathrm{n}=1$ ). Cytomegalovirus was found in BAL from 6 patients, in the healthy lungs of 5 patients, and in the lung tumors of 2 patients. Among the 13 positive CMV patients, detection was confirmed by two repeated CMV-PCR in 10 patients.

In the first part of the microbiological analysis, realtime PCR screening showed that 6 patients were positive for 16s ribosomal RNA. However, after standard PCR amplification and sequencing methods, these 6 amplicons were found to be of human origin, not from bacteria. A second round of DNA extraction and 16s ribosomal RNA PCR amplification was performed on these negative samples. Moreover, all traditional control cultures remained negative. These false-positive patients were con- sidered to be noncolonized. Accordingly, they were added to the 68 remaining patients with completely negative PCR to constitute the negative-PCR group ( $\mathrm{n}=$ 74 patients).

\section{Positive-PCR and Negative-PCR Groups}

There was no significant difference in term of clinical characteristics between the two groups, according to the PCR results (Table 1). Patients with positive PCR had a trend toward more severe alteration of diffusion lung capacity for carbon monoxide (DLCO), altered global functional status (New York Heart Association score), increased diabetes mellitus, increased global tobacco consumption, and more frequent previous thoracic surgery.

\section{Postoperative Outcome}

Of the 87 patients, $27(31 \%)$ had postoperative respiratory complications, with a median delay of 4 days (range, 1 to 21). According to the PCR results, 18 patients $(24 \%)$ had respiratory complications in the negative-PCR group, compared with $9(69 \%)$ in the colonized group $(p=0.003)$. Pneumonia occurred in 6 patients $(8 \%)$ of the negativePCR group and in 4 patients $(31 \%)$ of the positive-PCR group ( $p=0.039$ ). Table 3 summarizes the main postoperative outcome according to the PCR results. In-hospital mortality was similar between the groups. The length of hospital stay was significantly longer in the positive-PCR group ( $p=0.043)$.

The details of the 27 patients having postoperative 
Table 3. Outcome of the 87 Patients According to the Polymerase Chain Reaction Result

\begin{tabular}{|c|c|c|c|c|}
\hline Outcome & $\begin{array}{c}\text { All } \\
\mathrm{n}=87(\%)\end{array}$ & $\begin{array}{c}\text { Negative PCR } \\
\mathrm{n}=74(\%)\end{array}$ & $\begin{array}{c}\text { Positive PCR } \\
\mathrm{n}=13(\%)\end{array}$ & $p$ Value \\
\hline Overall complications & $43(49,4)$ & $32(43)$ & $11(84)$ & 0.006 \\
\hline Atelectasis & $11(13)$ & $8(10)$ & $3(23)$ & 0.210 \\
\hline Postoperative pneumonia & $10(11)$ & $6(8)$ & $4(31)$ & 0.039 \\
\hline ARDS & $6(7)$ & $4(5)$ & $2(15)$ & 0.218 \\
\hline Pneumothorax & $1(1)$ & $1(1)$ & $0(0)$ & 1.000 \\
\hline Need for mechanical ventilation & $8(9)$ & $5(7)$ & $3(23)$ & 0.094 \\
\hline Noninvasive ventilation & $10(11)$ & $8(11)$ & $2(15)$ & 0.461 \\
\hline Bronchoscopic suctioning & $13(14)$ & $8(11)$ & $5(38)$ & 0.022 \\
\hline Cardiac arrhythmia & $9(10)$ & $8(11)$ & $1(8)$ & 0.784 \\
\hline Recurrent injury & $4(5)$ & $4(5)$ & $0(0)$ & 1.000 \\
\hline Antibiotics & $20(23)$ & $12(16)$ & $8(61)$ & $<0.001$ \\
\hline Hospital mortality & $3(3)$ & $3(4)$ & $0(0)$ & 1.000 \\
\hline Length of hospital stay, median (range) & $9(4-66)$ & $9(4-61)$ & $14(7-66)$ & 0.043 \\
\hline
\end{tabular}

Data shown as n (\%) unless otherwise indicated.

ARDS $=$ acute respiratory distress syndrome; $\quad$ PCR $=$ polymerase chain reaction.

respiratory complications are provided in Table 4 . Postoperative cultures were positive in 18 patients $(67 \%)$ and negative in the remaining 9 patients $(33 \%)$. The postoperative microbiological findings are detailed in Table 5. Among the 9 positive-PCR patients with postoperative respiratory complications, 1 had pneumonia with concordant preoperative and postoperative microorganisms (CMV). Of the 8 remaining patients, concordance between preoperative and postoperative samples remained inconclusive due to negative cultures (Table 6).

\section{Multivariate Analysis}

We conducted two multivariate analyses to discriminate which factors were likely to influence occurrence of postoperative respiratory complications and the risk factors of a positive PCR.

In the first model dedicated to discriminate variables affecting postoperative respiratory complications, we have selected all variables with $p$ less than 0.1 in univariate analysis (Table 6). Accordingly, we have included in the logistic regression model eight variables: performance status, percent of predicted forced expiratory volume in 1 second, percent of predicted DLCO, alcohol, American Society of Anesthesiologists score, New York Heart Association score, chronic obstructive pulmonary disease, and positive PCR. Because of the small size of the cohort, we have opted for a stepwise analysis. After several steps and after adjustment of cofounders, we have obtained a final model including three independent and significant variables: performance status, percent of predicted DLCO, and positive PCR (Table 7).

In the second model dedicated to discriminate which factors were likely associated with positive-PCR, we have selected all variables with $p$ less than 0.1 in univariate analysis (Table 1). Accordingly, we have included in the logistic regression model three variables: percent of predicted Dlco, New York Heart Association score, and diabetes mellitus. Because of the small size of the cohort, we have opted for a stepwise analysis. After several steps and after adjustment of cofounders, the final model did not reach significance for any variables including in the logistic regression.

\section{Sensitivity and Specificity of Positive PCR on Postoperative Respiratory Complications}

We also conducted analyses to test reliability of positive PCR in the prediction of respiratory complications. The positive predictive value was 0.70 ( $95 \%$ confidence interval $[\mathrm{CI}], 0.44$ to 0.94$)$, and the positive likelihood ratio was 5 (95\% CI, 1.68 to 14.82$)$, whereas the negative predictive value was 0.75 ( $95 \% \mathrm{CI}, 0.52$ to 0.99$)$, and the negative likelihood ratio was $0.714(95 \% \mathrm{CI}, 0.54$ to 0.94$)$. The sensitivity of positive-PCR was $33 \%(95 \% \mathrm{CI}, 15 \%$ to $51 \%$, with a specificity of $93 \%$ ( $95 \%$ CI, $87 \%$ to $99 \%)$. The area under the receiver-operating characteristic curve was 0.725 ( $p=0.01 ; 95 \% \mathrm{CI}, 0.56$ to 0.88 ).

\section{Comment}

Whereas microbiota found in proximal airways of patients undergoing lung cancer surgery is well documented [5-12], the available microbiological data concerning distal airways and lung parenchyma at the moment of surgery remain conflicting. When investigated by culture-independent techniques, distal airways and lung parenchyma of patients undergoing lung cancer resection seem to be free from bacteria. Our results differ from previous reports that used phenotypic culture methods. Wansbrough-Jones and colleagues [13] have documented bacteria cultured in $22 \%$ of lavage specimens from resected lung. Loanas and associates [8] have also reported positives cultures from lung tissue in $8 \%$ of the resected specimens. In contrast, Schlusser and colleagues [5] have shown that cultures from lung tissue or from distal airways remained negative. 


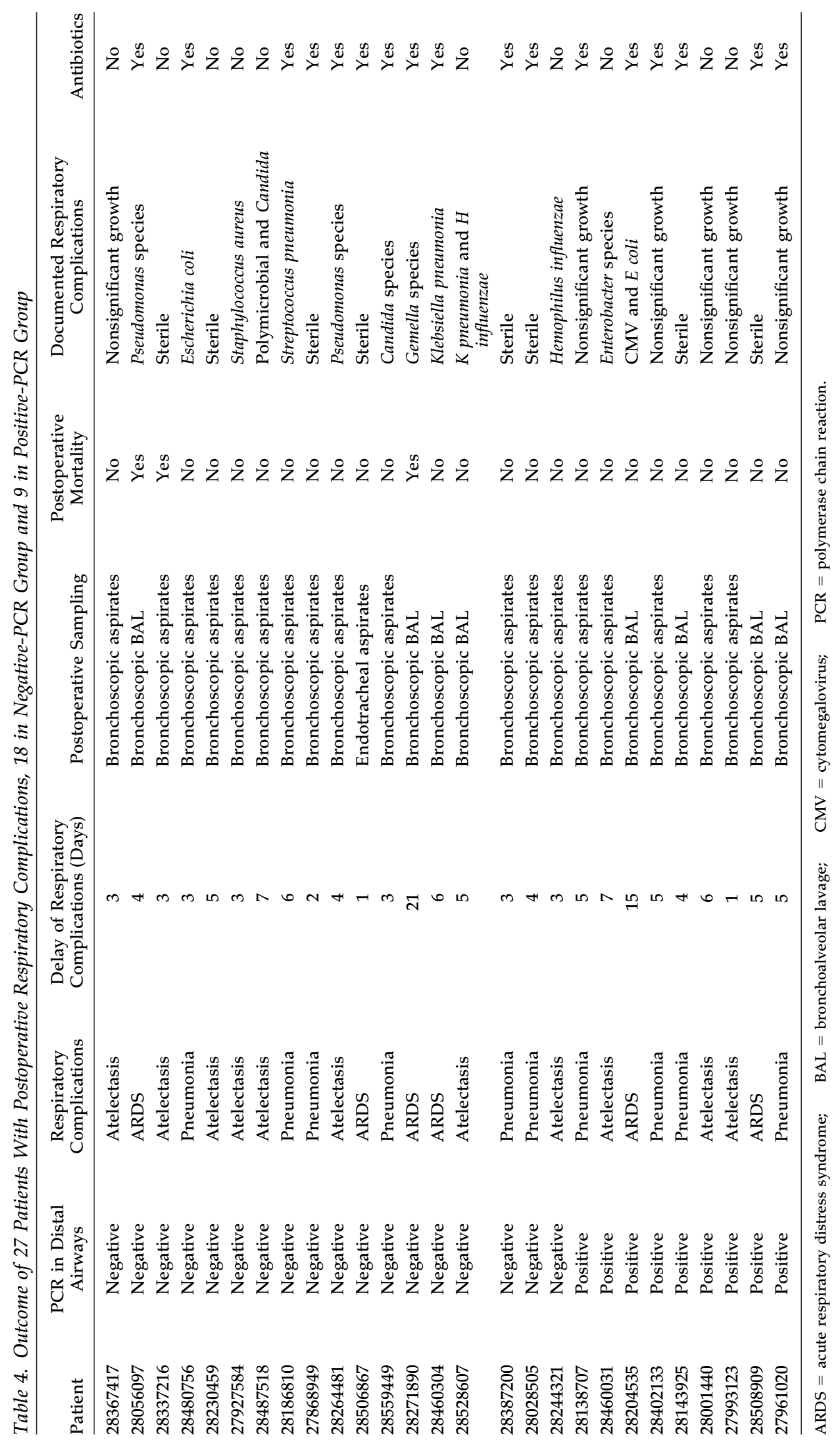




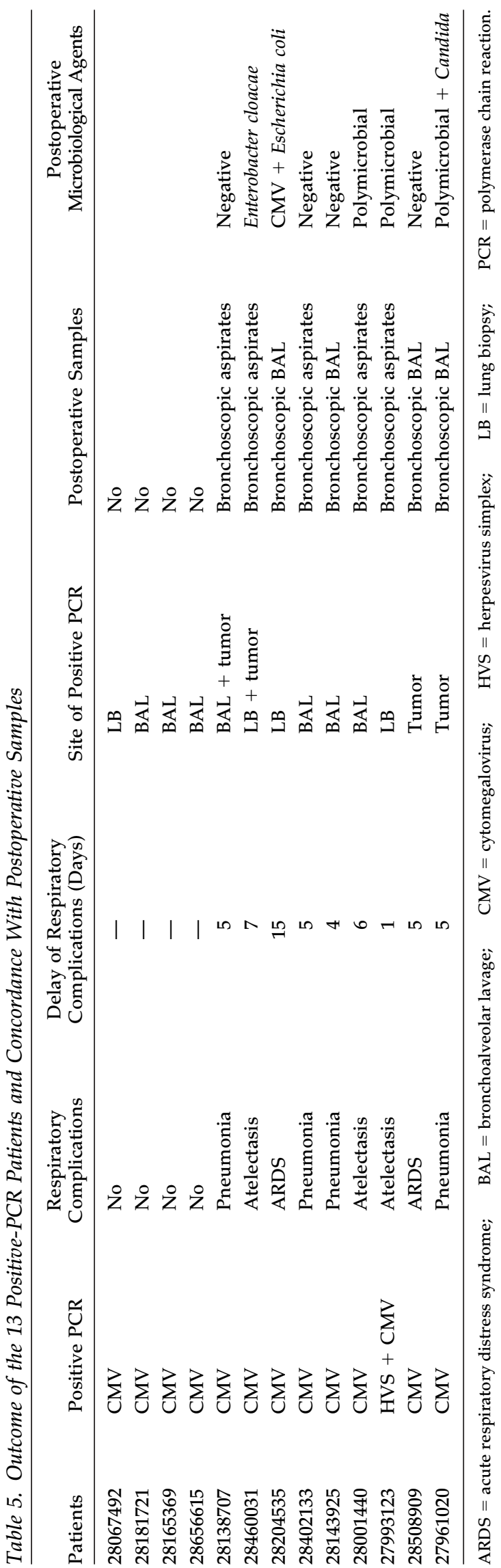

Taking into account, first, that distal airways and lung parenchyma are free of bacteria at the time of surgery, and second, that these distal airways will be the sites of postoperative infection, respiratory complications should be seen as the result of infection by pathogens originating in the upper respiratory or digestive tracts during the first postoperative days. Culture-independent techniques and metagenomic studies applied to samples obtained from these tissues could be extremely relevant to document a specific microbiota and investigate its potential role in the pathogenesis of respiratory failure [25-30].

If distal airways and lung parenchyma are free of bacteria, these sites present a high proportion of positive CMV real-time PCR $(15 \%)$. Of interest is the significant clinical association between the positive CMV real-time PCR and the risk of developing postoperative pulmonary complications. What remains unclear is whether positive CMV real-time PCR in distal airways is the result of the viral replication of a potential pathogen or, conversely, the result of reactivation from latency under specific local conditions or because of poor immunologic status.

There are more arguments for the belief that positive PCR is the result of a reactivation from latency. In critically ill immunocompetent patients, severe immunologic impairment is usually considered [31]. Cytomegalovirus is now recognized as an emerging pathogen in this context of "intensive care unit (ICU)-acquired immunosuppression" [16, 17, 32-34]. Recently, a group from our institution has demonstrated that active CMV infection was present in $16 \%$ of previously healthy medical ICU patients under mechanical ventilation [34]. The incidence was in agreement with results from both a recent study conducted in a French surgical ICU, which found CMV infection in $17 \%$ of critically ill patients [35], and a North American study documenting CMV reactivation in $30 \%$ of critically ill immunocompetent patients [36]. Outside the context of the ICU, our group has reported that CMV could be found in the airways of $9 \%$ of patients after chemoradiotherapy for esophageal cancer [17].

In the context of an oncologic disease favoring viral replication from latency, CMV reactivation should be seen as a marker for poor immunologic status rather than a potential pathogen. It is likely that a local or general inflammatory immune response is the natural stimulus for reactivation of CMV. It has been demonstrated in mice that elevated tumor necrosis factor- $\alpha$ levels in blood during systemic inflammatory response syndrome or sepsis might promote CMV reactivation [37, 38]. Reactivation of CMV may, therefore, be secondary to other infections, and the viral reactivation may be a part of the host's inflammatory response to that infection [39, 40].

Reactivation of CMV is likely present at the time of surgery because of the short delay between the induction of anesthesia and the observation of microbiological samples from resected lung. Lung cancer, smoking, chronic obstructive pulmonary disease, and diabetes mellitus are some factors that would favor this reactivation. Because the CMV PCR analysis was performed post 


\begin{tabular}{|c|c|c|c|}
\hline Factors & $\begin{array}{c}\text { No Postoperative Respiratory } \\
\text { Complications } \\
n=60(\%)\end{array}$ & $\begin{array}{c}\text { Postoperative Respiratory } \\
\text { Complications } \\
n=27(\%)\end{array}$ & $p$ Value \\
\hline \multicolumn{4}{|l|}{ Preoperative clinical status } \\
\hline Age, years, mean \pm SD & $63 \pm 8$ & $63 \pm 11$ & 0.971 \\
\hline Male & $42(70)$ & $20(74)$ & 0.801 \\
\hline Weight, $\mathrm{kg}$ (mean $\pm \mathrm{SD})$ & $69 \pm 19$ & $72 \pm 15$ & 0.512 \\
\hline Performance status & $0.12 \pm 0.3$ & $0.41 \pm 0.5$ & 0.003 \\
\hline Body mass index & $24 \pm 3$ & $23 \pm 4$ & 0.463 \\
\hline Charlson score & $4.8 \pm 1$ & $4.7 \pm 1$ & 0.918 \\
\hline $\mathrm{FEV}_{1} \%$ of predicted & $86 \pm 18$ & $78 \pm 16$ & 0.090 \\
\hline DLCO $\%$ of predicted & $75 \pm 11$ & $65 \pm 13$ & $<0.001$ \\
\hline \multicolumn{4}{|c|}{ Preoperative risk factors for respiratory complications } \\
\hline NSCLC & $52(86)$ & $22(81)$ & 0.531 \\
\hline Smoking history & $53(88)$ & $26(96)$ & 0.426 \\
\hline Smoking cessation ( $\mathrm{n}=79$ smokers $)$ & $40(66)$ & $17(63)$ & 0.800 \\
\hline Alcohol & $4(7)$ & $6(22)$ & 0.064 \\
\hline COPD & $17(28)$ & $16(59)$ & 0.009 \\
\hline Diabetes mellitus & $8(13)$ & $4(15)$ & 1.000 \\
\hline Previous cancer & $19(32)$ & $9(34)$ & 1.000 \\
\hline Previous CRT & $17(29)$ & $6(23)$ & 0.600 \\
\hline Neoadjuvant CRT & $5(8)$ & $4(14)$ & 0.450 \\
\hline ASA score & $1.9 \pm 0.5$ & $2.15 \pm 0.6$ & 0.070 \\
\hline NHYA score & $1.6 \pm 0.5$ & $1.8 \pm 0.5$ & 0.068 \\
\hline Previous cardiac disease & $9(14)$ & $3(11)$ & 1.000 \\
\hline Arterial hypertension & $7(12)$ & $5(18)$ & 0.500 \\
\hline Positive PCR & $4(6)$ & $9(33)$ & 0.002 \\
\hline \multicolumn{4}{|l|}{ Details of operation } \\
\hline Lobectomy & $55(91)$ & $25(92)$ & 1.000 \\
\hline Pneumonectomy & $3(3)$ & 0 & 1.000 \\
\hline Previous thoracic surgery & $3(5)$ & $2(7)$ & 0.640 \\
\hline Right side & $38(63)$ & $22(59)$ & 0.812 \\
\hline Epidural analgesia & $45(75)$ & $20(74)$ & 1.000 \\
\hline Hospital mortality & 0 & $3(11)$ & 0.028 \\
\hline Length of hospital stay, median (range) & $8(4-15)$ & $18(5-66)$ & $<0.001$ \\
\hline
\end{tabular}

Data presented as $\mathrm{n}(\%)$ or mean $\pm \mathrm{SD}$, unless otherwise indicated.

ASA = American Society of Anesthesiologists; $\quad$ COPD $=$ chronic obstructive pulmonary disease; $\quad$ CRT $=$ chemoradiotherapy; $\quad$ DLCO $=$ diffusion lung capacity for carbon monoxide; $\quad \mathrm{FEV}_{1}=$ forced expiratory volume in 1 second; $\quad$ NSCLC $=$ non-small cell lung cancer; $\quad$ NYHA $=$ New York Heart Association; $\quad$ PCR = polymerase chain reaction.

hoc, it seems speculative to conclude which factors should be considered indicative of the risk of viral reactivation. Complete individualization of clinical fac-

Table 7. Multivariate Analysis of Factors of Postoperative Respiratory Complications

\begin{tabular}{|c|c|c|c|c|}
\hline \multirow{2}{*}{$\begin{array}{l}\text { Postoperative } \\
\text { Respiratory } \\
\text { Complication Factors }\end{array}$} & \multirow[b]{2}{*}{$p$ Value } & \multirow{2}{*}{$\begin{array}{l}\text { Odds } \\
\text { Ratio }\end{array}$} & \multicolumn{2}{|c|}{$\begin{array}{l}95 \% \text { Confidence } \\
\text { Interval }\end{array}$} \\
\hline & & & Low & High \\
\hline DLCO $\%$ of predicted & 0.016 & 0.94 & 0.899 & 0.989 \\
\hline Performance status & 0.009 & 4.9 & 1.49 & 16.2 \\
\hline Positive PCR & 0.013 & 7.39 & 1.525 & 35.8 \\
\hline
\end{tabular}

DLCO $=$ diffusion lung capacity for carbon monoxide; $\quad$ PCR $=$ polymerase chain reaction. tors affecting CMV reactivation is probably too large and complex to be revealed by this limited study and requires prospective evaluation to be highlighted.

One of the two strongest limitations of our study is the lack of consistent CMV PCR results in the proximal airways and on all the postoperative microbiological samples. Among the 13 positive-PCR patients, 12 had no postoperative CMV assessment, and only 1 had documented CMV in bronchoscopic BAL. Prospective assessment of these samples with a simultaneous assessment of CMV plasma DNAemia by real-time PCR should have been the most appropriate method of identification, as previously reported [36].

The second limitation remains the small sample size of our cohort. That can be explained by our study being an observational study of a homogeneous cohort of consec- 
utive patients who underwent a standardized surgical approach. Moreover, our study was designed to be limited in time ( 9 months) to provide homogeneous data. Despite these specific biases inherent to clinical investigations, we believe that our study provides substantial new information. With a strong specificity and a good positive predictive value, regular CMV real-time PCR in distal airways at the moment of the surgery should be seen as a biological marker to identify a subgroup of patients who are at high risk for the development of respiratory complications. This method could provide an indirect marker of the global immunologic status and, more specifically, the status of the airways. The cost of a CMV real-time PCR does not exceed $€ 100$ (\$135), and the results are available within few hours. As a result, application of this technique in daily practice deserves further investigation for early detection in patients presenting CMV reactivation in distal airways.

In conclusion, when tested by molecular techniques, lung parenchyma and distal airways are free of bacteria but positive CMV real-time PCR is found in a high proportion of samples. Reactivation of CMV in this context seems to be an indicator of an ongoing inflammatory process or a biological marker of poor immunologic status. With a good positive predictive value, detection of this viral reactivation by PCR should be seen as a reliable biological marker to identify patients who are at high risk for developing respiratory complications.

Supported by the Grant for Research in Thoracic Surgery, Generation Thorax, Paris, France.

\section{References}

1. Watanabe S, Asamura H, Suzuki K, Tsuchiya R. Recent results of postoperative mortality for surgical resections in lung cancer. Ann Thorac Surg 2004;78:999-1002.

2. Wada HT, Nakamura N, Nakamoto K, Maeda M, Watanabe Y. Thirty-day operative mortality for thoracotomy in lung cancer. J Thorac Cardiovasc Surg 1998;115:70-3.

3. Radu DM, Jauréguy F, Seguin A, et al. Postoperative pneumonia after major pulmonary resections: an unsolved problem in thoracic surgery. Ann Thorac Surg 2007;84:1669-73.

4. Bernard AC, Deschamps C, Allen MS, et al. Pneumonectomy for malignant disease: factors affecting early morbidity and mortality. J Thorac Cardiovasc Surg 2001;121:1076-82.

5. Schussler O, Alifano M, Dermine $\mathrm{H}$, et al. Postoperative pneumonia after major lung resection. Am J Respir Crit Care Med 2006;173:1161-9.

6. Cabello H, Torres A, Celis R, et al. Bacterial colonization of distal airways in healthy subjects and chronic lung disease: a bronchoscopic study. Eur Respir J 1997;10:1137-44.

7. Belda J, Cavalcanti M, Ferrer M, et al. Bronchial colonization and postoperative respiratory infections in patients undergoing lung cancer surgery. Chest 2005;128:1571-9.

8. Ioanas M, Angrill J, Baldo $X$, et al. Bronchial bacterial colonization in patients with resectable lung carcinoma. Eur Respir J 2002;19:326-32.

9. Torres A. Respiratory infections after lung cancer resection. Expert Rev Anti Infect Ther 2006;4:717-20.

10. Sok M, Dragas AZ, Erzen J, Jerman J. Sources of pathogens causing pleuropulmonary infections after lung cancer resection. Eur J Cardiothorac Surg 2002;22:23-7.

11. Yamada Y, Sekine Y, Suzuki H, et al. Trends of bacterial colonisation and the risk of postoperative pneumonia in lung cancer patients with chronic obstructive pulmonary disease. Eur J Cardiothorac Surg 2010;32:752-7.

12. D'Journo XB, Rolain JM, Doddoli C, Raoult D, Thomas PA. Airways colonizations in patients undergoing lung cancer surgery. Eur J Cardiothorac Surg 2011;40:309-19.

13. Wansbrough-Jones MH, Nelson A, New L, Wilson A, Wright N, Pepper JR. Bronchoalveolar lavage in the prediction of post-thoracotomy chest infection. Eur J Cardiothorac Surg 1991;5:433-4.

14. Pace NR. A molecular view of microbial diversity and the biosphere. Science 1997;276:734-40.

15. Amann RI, Ludwig W, Schleifer KH. Phylogenetic identification and in situ detection of individual microbial cells without cultivation. Microbiol Rev 1995;59:143-69.

16. Papazian L, Fraisse A, Garbe L, et al. Cytomegalovirus. An unexpected cause of ventilator-associated pneumonia. Anesthesiology 1996;84:280-7.

17. D'Journo XB, Michelet P, Papazian L, et al. Airway colonisation and postoperative pulmonary complications after neoadjuvant therapy for oesophageal cancer. Eur J Cardiothorac Surg 2008;33:444-50.

18. Maskell NA, Batt S, Hedley EL, Davies CW, Gillespie SH, Davies RJ. The bacteriology of pleural infection by genetic and standard methods and its mortality significance. Am J Respir Crit Care Med 2006;174:817-23.

19. Menéndez R, Córdoba J, de La Cuadra P, et al. Value of the polymerase chain reaction assay in noninvasive respiratory samples for diagnosis of community-acquired pneumonia. Am J Respir Crit Care Med 1999;159:1868-73.

20. Bittar F, Richet H, Dubus JC, et al. Molecular detection of multiple emerging pathogens in sputa from cystic fibrosis patients. PLoS One 2008;3:e2908.

21. Griscelli F, Barrois M, Chauvin S, Lastere S, Bellet D, Bourhis JH. Quantification of human cytomegalovirus DNA in bone marrow transplant recipients by real-time PCR. J Clin Microbiol 2001;39:4362-9.

22. Kessler HH, Muhlbauer G, Rinner B, et al. Detection of herpes simplex virus DNA by real-time PCR. J Clin Microbiol 200;38:2638-42.

23. Dridi B, Henry M, El Khéchine A, Raoult D, Drancourt M. High prevalence of Methanobrevibacter smithii and Methanosphaera stadtmanae detected in the human gut using an improved DNA detection protocol. PLoS One 2009;4:e7063.

24. Bernard GR, Artigas A, Brigham KL, et al. The AmericanEuropean consensus conference on ARDS. Definitions, mechanisms, relevant outcomes, and clinical trial coordination. Am J Respir Crit Care Med 1994;149:818-24.

25. Armougom F, Bittar F, Stremler N, et al. Microbial diversity in the sputum of a cystic fibrosis patient studied with $16 \mathrm{~S}$ rDNA pyrosequencing. Eur J Clin Microbiol Infect Dis 2009;28:1151-4.

26. Harris JK, De Groote MA, Sagel SD, et al. Molecular identification of bacteria in bronchoalveolar lavage fluid from children with cystic fibrosis. Proc Natl Acad Sci USA 2007; 104:20529-33.

27. Petrosino JF, Highlander S, Luna RA, Gibbs RA, Versalovic J. Metagenomic pyrosequencing and microbial identification. Clin Chem 2009;55:856-66.

28. Andersson AF, Lindberg M, Jakobsson H, Bäckhed F, Nyrén $P$, Engstrand L. Comparative analysis of human gut microbiota by barcoded pyrosequencing. PLoS One 2008;3:e2836.

29. Gill SR, Pop M, Deboy RT, et al. Metagenomic analysis of the human distal gut microbiome. Science 2006;312:1355-9.

30. Willner D, Furlan M, Haynes M, et al. Metagenomic analysis of respiratory tract DNA viral communities in cystic fibrosis and non-cystic fibrosis individuals. PLoS One 2009;4:e7370.

31. Munford RS, Pugin J. Normal responses to injury prevent systemic inflammation and can be immunosuppressive. Am J Respir Crit Care Med 2001;163:316-21.

32. Osawa R, Singh N. Cytomegalovirus infection in critically ill patients: a systematic review. Crit Care 2009;13:R68. 
33. Cunha BA. Cytomegalovirus pneumonia: communityacquired pneumonia in immunocompetent hosts. Infect Dis Clin North Am 2010;24:147-58.

34. Chiche L, Forel JM, Roch A, et al. Active cytomegalovirus infection is common in mechanically ventilated medical intensive care unit patients. Crit Care Med 2009;37:1850-7.

35. Jaber S, Chanques G, Borry J, et al. Cytomegalovirus infection in critically ill patients: associated factors and consequences. Chest 2005;127:233-41.

36. Limaye AP, Kirby KA, Rubenfeld GD, et al. Cytomegalovirus reactivation in critically ill immunocompetent patients. JAMA 2008;300:413-22.
37. Simon CO, Seckert CK, Dreis D, Reddehase MJ, Grzimek NK. Role for tumor necrosis factor alpha in murine cytomegalovirus transcriptional reactivation in latently infected lungs. J Virol 2005;79:326-40.

38. Cook CH, Zhang Y, Sedmak DD, Martin LC, Jewell S, Ferguson RM. Pulmonary cytomegalovirus reactivation causes pathology in immunocompetent mice. Crit Care Med 2006;34:842-9.

39. Hummel M, Abecassis MM. A model for reactivation of CMV from latency. J Clin Virol 2002;25:123-36.

40. Sinclair J, Sissons P. Latency and reactivation of human cytomegalovirus. J Gen Virol 2006;87:1763-79. 